\title{
A Clinical Study on Association of Helicobacter Pylori Infection With Type-2 Diabetes And Depression
}

\author{
Dr. R. P. Das ${ }^{1}$, Dr. D. Medhi ${ }^{2}$, Dr.R.Mathur ${ }^{3}$
}

\begin{abstract}
H$. pylori is a common chronic infectious-inflammatory disease worldwide. Association of this infection with type II Diabetes is found in many studies. There is recent discussion on 'inflammatory hypothesis' and immunological mechanisms involved in causation of Depression. The current study tries to see the association of $\mathrm{H}$. pylori infection in 40 patients of type II Diabetes and presence of depression among them. Study findings supports the association showing that the patients of Diabetes had statistically significant higher numbers of positive H. Pylori. The study also found higher presence of depression among $H$. pylori positive diabetic patients than $H$. pylori negative diabetic patients proving the hypothesis.
\end{abstract}

Keywords: H. pylori, Type II Diabetes, Depression.

\section{Introduction}

chronic inflammation may be a major cause of type 2 diabetes ${ }^{2,3,4,5,6}$, the association of chronic $\mathrm{H}$. pylori infection with type 2 diabetes has been widely discussed. Previous studies have suggested a higher prevalence of $\mathrm{H}$. pylori infection in patients with diabetes ${ }^{7,8,9,10}$. However other studies ${ }^{11,12,13}$ did not reveal significant association of this infection in diabetic patients.

event in the development of glucose intolerance or type 2 diabetes ${ }^{1,7}$. Glycosylated haemoglobin $(\mathrm{Hb} 1 \mathrm{Ac})$ reflects long-term glycemic status and is a more stable measurement than fasting blood sugar for DM. To clarify whether chronic H.pylori infection is a risk factor for type 2 diabetes, it is very important to understand the effects of chronic $\mathrm{H}$. pylori infection on glucose regulation including HbA1c.Research in this area in Indian sub-continent is almost non-existent. This study aims to identify the possible association between H.pylori infection and glucose dysregulation in Indian population.

The inflammatory hypothesis of depression is a recently discussed one. The role of cytokines in Depression was first proposed by Smith et $\mathrm{al}^{14}$ in the form of the 'Macrophage theory of depression' and further studied by Maes et $\mathrm{al}^{15}$ in early 1990s. Patients with severe clinical depression have increased blood levels of inflammatory bio-markers. But the cause- effect relationship is yet to be understood .However in response to peripheral infection, innate immune cells produce pro-inflammatory cytokines that act on the brain to cause sickness behavior. When activation of the peripheral immune system continues unabated such as during systemic infection, cancer or auto-immune disease, the ensuing immune signaling to the brain can lead to an exacerbation of sickness and the development of symptoms of depression in vulnerable individuals. Inflammation is therefore an important biological event that might increase the risk of major depressive episodes, much like more than the traditional psychological factors. Thus the Hypothesis for the study was that Chronic infections like H. pylori infection are more common in Type II Diabetes and may contribute to its etiopathogenesis and also to pathogenesis of depression in them.

\section{Aims And Objectives}

1. To assess the prevalence of H.pylori infection in patients of type II Diabetes Mellitus.

2. To identify the association between chronic H.pylori infection and type 2 diabetes mellitus as a risk factor for DM-II.

3. To see the prevelance of Depression in patients with type 2 Diabetes Mellitus and to compare the prevelance in respect to presence or absence of $\mathrm{H}$. pylori infection in them.

\section{Methods And Materials}

A cross-sectional, prospective ,hospital based research design method was adopted for the study. The study was carried out in the department of Psychiatry, Gauhati Medical College, Assam from $1^{\text {st }}$ Sept, 2014 to $31^{\text {st }}$ August, 2015 and it received ethical clearance from the Institutional Ethical Committee of Gauhati Medical College.

The patients with type II Diabetes attending the indoor and outdoor of medicine department of Gauhati Medical College \& Hospital were included using serial sampling method aged between 25-65 years. The Informed Consent was obtained from the participants before administering the Testing tools described below. A total of 100 cases participated in the study. 
Inclusion criteria: All Patients of both sexes and between age 25-65 years were included giving informed consent.

Exclusion criteria: Patients with severe diabetic complications; patients with different other gastro-intestinal diseases like Ulcerative Colitis, Crohn's disease etc; patients with unstable hyperglycaemic symptoms like weight loss, polyuria, polydypsia, polyphagia etc; and patients who received treatment for H. pylori infection within 6 months prior to the recruitment into the study were excluded.

\section{Testing tools:}

1. Socio-demographic data sheet: It is a semi-structured proforma, especially prepared for the study by the authors. It contained information about socio-demographic variables like age, sex, religion, education, marital -status, occupation, residential status etc. It also contained informations about patient's bodyweight, height, blood- pressure etc.

2. The diagnosis of type 2 diabetes mellitus was based on American Diabetes Association criteria (17). The patients received a complete physical examination and a host of laboratory tests including fasting \&PP blood sugar, HbA1c level etc.

3. Diagnosis of H. pylori infection was established using a commercial kit known as Bio-line H-pylori kit for in-vitro diagnosis of antibodies to H-pylori manufactured by Biostandard diagnostic Pvt. Ltd., Gurgaon. 4.

4. The subjects were also assessed for presence of Depression using Hamilton Depression rating scale-21 item (1960).

5. Informed Consent Form.

\section{Results}

Data of 100 patients $($ Male=50,Female=50) with Diabetes Mellitus- type II attending the indoor and outdoor of Medicine department of Gauhati Medical College \& Hospital from $1^{\text {st }}$ September, 2013 to $1^{\text {st }}$ August , 2014 were obtained. SAS (9.12 software Version) was used for all kinds of statistical analysis. On evaluation, 50 males and 50 females fulfilled the selection criteria and were included in the study. The mean age of the sample was 41.71 yrs. The mean HbA1c of the sample was 7.63 and the mean duration of Diabetes was 3.45 yrs.(table 1\&2).

Table-1 Sociodemographics

\begin{tabular}{|l|l|l|}
\hline Total Patients & No. of Males & No. of Females \\
\hline 100 & 50 & 50 \\
\hline
\end{tabular}

Table-2

\begin{tabular}{|l|l|}
\hline Mean age of the sample & 41.71 years \\
\hline Mean HbA1c of the sample & 7.63 \\
\hline Mean duration of diabetes & 3.45 years \\
\hline Prevelance of depression in the sample & $34 \%$ \\
\hline H. pylori positivity percentage & $62 \%$ \\
\hline
\end{tabular}

Table-3 H. Pylori Positivity \& Depression

\begin{tabular}{|l|l|l|l|}
\hline & H.pylori positive & H. pylori negative & Total \\
\hline Clinically depressed & 27 & 7 & 34 \\
\hline Clinically non-depressed & 35 & 31 & 66 \\
\hline Total & 62 & 38 & 100 \\
\hline
\end{tabular}

Table-4

\begin{tabular}{|l|l|l|}
\hline & H. pylori positive & H. pylori negative \\
\hline No. of patients & 62 & 38 \\
\hline Mean age & 41.64 years & 41.81 years \\
\hline Mean HbA1c & 7.69 & 7.54 \\
\hline Duration of diabetes & 3.64 years & 3.13 years \\
\hline Prevelance of Depression & $43.5 \% *$ & $18.4 \% *$ \\
\hline
\end{tabular}

*statistically significant difference-p $<0.05$ (chi square method) 
A Clinical Study On Association Of Helicobacter Pylori Infection With Type-2 Diabetes ..

Table-5

\begin{tabular}{|l|l|l|l|l|l|}
\hline & $\begin{array}{l}\text { TOTAL } \\
\text { DEPRESSED }\end{array}$ & $\begin{array}{l}\text { MILDLY } \\
\text { DEPRESSED }\end{array}$ & $\begin{array}{l}\text { MODERATELY } \\
\text { DEPRESSED }\end{array}$ & $\begin{array}{l}\text { SEVERELY } \\
\text { DEPRESSED }\end{array}$ & $\begin{array}{l}\text { VERY } \\
\text { SEVERELY } \\
\text { DEPRESSED }\end{array}$ \\
\hline No. of patients & 34 & 12 & 11 & 8 & 3 \\
\hline Mean HbA1c & 8.08 & 7.8 & 5 & 8.7 & 8.5 \\
\hline $\begin{array}{l}\text { Mean duration of } \\
\text { DM(in years) }\end{array}$ & 4.52 & 5.33 & 7.83 & 3.25 & 1.66 \\
\hline H.pylori positivity & $79.41 \%$ & $75 \%$ & $72 \%$ & $87.5 \%$ & $100 \%$ \\
\hline
\end{tabular}

In the sample, 62 no. of diabetic patients were found to be H. pylori positive (62\%) and 38 no.(38\%) of diabetic patients were $\mathrm{H}$. pylori negative.(Table-3) Mean age of the H. pylori positive cases were 41.64 years and mean age of the $\mathrm{H}$. pylori negative cases were 41.1 years. Mean HbA1c in H. pylori positive group was 7.69. and H. pylori negative group was 7.54. Duration of Diabetes in the H. pylori positive group was 3.64 years vs 3.13 years in $\mathrm{H}$. pylori negative group (Table 4)

The prevelance of depression in the sample was $34 \%$ following use of Hamilton Depression rating scale-21 item at cut-off score of 7 .(34- depressed, 66- non-depressed-Table 3). Mean HbA1c level of depressed patients was 8.08. Mean HAM-D score of depressed patients was found to be $15.79 .42 \%$ male patients and $26 \%$ female patients were found to be clinically depressed. Out of 34 depressed patients, 12 patients had Mild depression( mean HbAc-7.8, mean duration=5.33yrs);11 had Moderate depression( mean HbA1c=5, mean duration=7.83 yrs); 8 had Severe depression ( mean $\mathrm{HbA1C}=8.7$, mean duration=3.25 yrs) and 3 patients had Very Severe depression. (mean HbA1c=8.5, Mean duration=1.66yrs)(table 4).

H. pylori positivity was found to be $75 \%, 72.7 \%, 87.5 \%$ and $100 \%$ in mild, moderate, severe and very severe depreesive groups respectively.(table 4)

When H. pylori positivity was compared with presence of depression in the sample, 27 nos $(79.4 \%)$ of depressed patients (out of 34 nos.of depressed) were found to be H. pylori positive and 7 nos. (20.6\%) depressed patients were H. pylori negative(table 3). $79.4 \%$ of depressed (27 out of 34 nos.) were H. pylori positive vs $53.03 \%$ ( 35 out of 66 ) of non-depressed were H. pylori positive. (table 3 ).

The total no. of H.pylori positive cases in the total sample(100 cases) were 62 and $\mathrm{H}$. pylori negative cases were 38 .Out of $62 \mathrm{H}$. pylori positive cases, 27 cases were clinically depressed(43.5\%) and 35(56.5\%) cases were non-depressed.(table 3). So, the prevelance of depression in the H. pylori positive group was $43.5 \%$. In the H. pylori negative group, the prevelance of depression was $18.42 \%$ ( 7 pts out of 38 ) and the difference was found to be statistically significant.( $p<0.05$, chi square method).(table 3 ).

[(chi square, df-6.629,1;p-value 0.0100*;two-sided; alpha<0.05;RR-1.497; 95\% confidence interval1.127 to 1.990 ; odds ratio-3.416, 95\% confidence interval- 1.306 to 8.939 . sensitivity- $0.4355 ; 95 \%$ confidence interval-0.3099 to 0.5674 ; specificity $-0.8158 ; 95 \%$ conf. interval-0.6567 to 0.9226 ; positive predictive value $0.7941 ; 95 \%$ confidence interval-0.6210 to 0.9130 ; negative predictive value $0.4697 ; 95 \%$ confidence interval 0.3456 to. 5966, likelihood ratio 2.364...)]. Following Yates' correction too, for the prevelance of depression in $\mathrm{H}$. pylori positive and negative group, the difference was statistically significant $(\mathrm{p}<0.05)$

In the H. pylori negative group (38 nos.), prevelance of depression was $18.42 \%$ only ( 7 patients) and the difference was statistically significant.

Among non-depressed (66 nos.), 35 patients (53.03\%) were H. pylori positive and31 patients (46.97\%) were H. pylori negative and the difference was statistically insignificant. $(\mathrm{p}>0.05)$.

When both H. pylori positive(62nos) and negative group(38 nos.) were further compared, the mean ages were $41.64 \mathrm{yrs}$ vs $41.81 \mathrm{yrs}$; mean HbA1c were 7.69 vs 7.54; mean duration of illness were $3 . .64$ yrs vs 3.13 yrs. respectively.

\section{Discussion}

In our study, 100 patients with type II Diabetes were analyzed for presence of depression and H. pylori positivity and their possible associations were tested. Our hypothesis was tested positive as $62 \%$ of the samples were H.pylori positive and $43.5 \%$ of H.pylori positive patients were depressed vs only $18.4 \%$ of H. Pylori negative patients were depressed and the difference was statistically significant.

That Helicobacter Pylori infection is one of the most common chronic inflammatory disease among the patients of Diabetes, was also reported by Bener A et al. ${ }^{1}$ H.pylori positivity in our sample was also very high (62\%) suggesting a causal association of chronic infection (H. Pylori) with type II Diabetes as reported by Quatrini $\mathrm{M}$ et $\mathrm{al}^{5}$ and Gulcelik NE et $\mathrm{al}^{6}$. High prevelance of $\mathrm{H}$. pylori infection in patients with Diabetes was also reported in studies by Quadri $\mathrm{R}$ et $\mathrm{al}^{7}$, Anastasios $\mathrm{R}$ et $\mathrm{al}^{8}, \mathrm{Ko}_{\mathrm{GT}}$ et $\mathrm{al}^{9}$ and Stanciu OG et $\mathrm{al}^{10}$.

The mean HbA1c of our study sample was 7.63. Mean HbA1c of H. pylori positive and negative patients were 7.69 and 7.54(p>0.05) respectively. 
The prevelance of depression in total study diabetic population was $34 \%$, but prevelance of depression in $\mathrm{H}$. pylori patients was $43.5 \%$ vs $18.4 \%$ in $\mathrm{H}$. pylori negative patients and the difference was statistically significant, thus establishes the inflammation (H. PYLORI) as important risk factor for depression in the infected group and also supports the inflammatory hypothesis of deression put forwarded by Smith et al and Maes et al. ${ }^{14,15}$

\section{Limitations}

Our study did not evaluate the sex differences of the H. pylori positivity(74\% in males vs $50 \%$ in females) in the sample. It was an open, hospital based, cross-sectional study. A case-control, community based study would be more helpful to evaluate 'Infection' as a cause for Type II Diabetes and to rule out other environmental confounding variables.

\section{Strength Of The Study:}

Though being an open kind of study, data were collected separately by the third author, who again remained blinded to the result assessment and also to study objectives.

\section{Future Directions \& Implications:}

The results of the study throw some light on the inflammatory hypothesis of type II diabetes mellitus and thus may affect the treatment outcome of type II diabetes mellitus. If the causative H. pylori infection is treated beforehand, it can lead to prevention of DM -II and depression associated with it.

\section{Conclusion}

This is the first-ever study done in India. The association of infective illness (H.pylori) in causation of type II Diabetes and Depression brings a new insight to the etiology of such illnesses and establishes the biological basis of depression and also psychological causation of type II Diabetes, which was acknowledged since long time from different researches done world-wide. Study results establish the inflammatory hypothesis of depression which is the new bio-immunological hypothesis other than classical Monoamine hypothesis of depression and thus brings insight about future treatment and primary prevention of both the illnesses.

\section{References}

[1]. Bener A, Micallef R, Afifi M,. Derbala M, Al-Mulla HM, Usmani MA. Association between type 2 diabetes mellitus and Helicobacter pylori infection. Turk J Gastroenterol 2007; 18:225-9

[2]. Fan XG, Chua A, Fan XJ, Keeling PW. Increased gastric production of interleukin-8 and tumour necrosis factor in patients with Helicobacter pylori infection.J Clin Pathol 1995; 48:133-6

[3]. Pradhan AD,Manson JE,Rifa N,Buring JE,Ridker PM.C-reactive protein, interleukin6, and risk of developing type 2 diabetes Mellitus.JAMA 2001;286:327-34

[4]. Senturk O, Canturk Z,Cetinarslan B,Ercin C, Hulagu S, Canturk NZ. Prevelance and comparisons of five different diagnostic methods for Helicobacter pylori in diabetic patients. Endrocr Res 2001; 27:179-89

[5]. Quatrini M, Boarino V, Ghidoni A, Baldassarri AR, Bianchi PA, Bardella MT. Helicobacter pylori prevelance in patients diabetes and its relationship to dyspeptic symptoms. J Clin Gastroenterol 2001;32:251-7

[6]. Gulcelik NE, Kaya E, Demirbas B, Culha C, Koc G, Ozkaya M et al. Helicobacter pylori prevelance in diabetic patients and its relationship with dyspepsia and autonomic neuropathy. J Endrocrinol Invest 2005; 28:214-7.

[7]. Quadri R, Rossi C, Catalfamo E, Masoero G, Lombardo L, Della Monica P et al.Helicobacter pylori infection in type 2 diabetes patients. Nutr Metab Cardiovas Dis 2000; 10:263-6.

[8]. Anastasios R, Goritsas C, Papamihail C, Trigodou R, Garzonis P, Ferti A. Helicobacter pylori infection in diabetic patients: prevelance and endoscopic findings. Eur J Intern Med 2002; 13:376

[9]. Ko GT, Chan FK, Chan WB, Sung JJ, Tsoi CL, To KF et al. Helicobacter pylori infection in Chinese subjects with type 2 diabetes. Endrocr Res 2001;27:171-7.

[10]. Stanciu OG, Triaafan A, Sfarti C, Cojocariu c, Stanciu C. Helicobacter pylori infection in patients with diabetes mellitus.Rev Med Chir Soc Med Nat Iasi 2003;107:59-65

[11]. Selvin E,Steffes MW, Zhu H, Matsuhita K, Wagenknecht L, Pankow J et al. Glycated haemoglobin, diabetes, and cardiovascular risk in nondiabetic adults.N Engl J Med $2010 ; 362: 800-11$

[12]. Ming-Chia Hsieh,Sophie S, W.Wang,Yi-Ting Hsieh,Fu-Chen Kuo,Maw-Soan Soon .EurJ Clin Invest 2013;43(9):949-956

[13]. Dantzer R, O'Connor JC, Freund GG, Johnson RW, Kelley KW. From inflammation to sickness and depression: when the immune system subjugates the brain. Nat Rev Neurosci. 2008; 9:46-56.[PubMed: 18073775]

[14]. 14.Karen Wager-Smith and Athina Markou.Depression: A repair response to stress-induced neuronal micro-damage that can grade into a chronic neuro-inflammatory condition? Neurosci Biobehav Rev. 2011 January;35(3):742-764.

[15]. 15.Maes M,Smith R,Scharpe S. The monocyte-T-lymphocyte hypothesis of major depresetion. Psychoneuroendocrinology 1995;20:111-116[Pub Med:7899532]

[16]. Raj Pratim Das, Assistant Professor of Medicine :Fakaruddin Ali Ahmed Medical College,Barpeta, Assam, India.

[17]. Deepanjali Medhi, Associate Professor of Psyciatry : Gauhati Medical College ,Guwahati,Assam , India.

[18]. Rahul Mathur, Post Graduate Trainee of Psychiatry, Gauhati Medical College, Guwahati, Assam , India. 